\title{
Research and Application of Globally Optimized Sequence Stratigraphic Seismic Interpretation Technology: Taking the Lower Cretaceous Shahezi Formation of Xujiaweizi Fault Depression as an Example
}

\author{
Xiaowei Guan $\mathbb{D}^{1,2}$ Qian Meng, ${ }^{1,2}$ Chuanjin Jiang, ${ }^{2}$ Xinyu Liu $\mathbb{D}^{1},{ }^{1}$ and Menglu Han ${ }^{2}$ \\ ${ }^{1}$ Northeast Petroleum University, Daqing, Heilongjiang 163318, China \\ ${ }^{2}$ Daqing Oilfield Exploration and Development Institute, Daqing, Heilongjiang 163712, China \\ Correspondence should be addressed to Xiaowei Guan; 183368904@qq.com and Xinyu Liu; 6xydtc@stu.nepu.edu.cn
}

Received 24 July 2021; Accepted 25 August 2021; Published 15 September 2021

Academic Editor: Xudong Zhang

Copyright ( 2021 Xiaowei Guan et al. This is an open access article distributed under the Creative Commons Attribution License, which permits unrestricted use, distribution, and reproduction in any medium, provided the original work is properly cited.

\begin{abstract}
In the study of sequence stratigraphy in continental rift basins, the use of seismic data to track different levels of sequence stratigraphic boundaries laterally is the key to the division of sequence stratigraphic units at all levels and the establishment of an isochronous sequence stratigraphic framework. Traditional seismic interpretation and the establishment of a 3D sequence stratigraphic structure model are a difficult research work. This paper introduces the concept of cost function minimization and performs global stratigraphic scanning on 3D seismic data to interpret horizons and faults in a large grid. Constrained by the results, human-computer interactive intelligent interpretation, by adding iterative interpretation of geological knowledge, established a global stratigraphic model with a relative geological age. The application in the Lower Cretaceous Shahezi Formation of Xujiaweizi fault depression shows that this technology has improved the accuracy and efficiency of sequence stratigraphic interpretation, and the application of this technology has achieved the interpretation of each event horizon under the current seismic data resolution conditions. In this way, a continuous sequence stratigraphic model is established. From this stratigraphic model, any high-frequency sequence-interpreted seismic horizon can be extracted, which provides a basis for the combination of lateral resolution and longitudinal resolution of subsequent reservoir prediction.
\end{abstract}

\section{Introduction}

With the continuous deepening of oil and gas exploration and development, deep tight gas in continental rift basins has gradually become a key area of unconventional natural gas exploration $[1,2]$. Under this situation, there is an urgent need to improve the accuracy and efficiency of sequence stratigraphic seismic interpretation in continental rift basins, increase the accuracy of stratigraphic prediction, and provide a scientific basis for exploration [3]. However, terrestrial rift basins are complex in structure, rapid in sedimentary facies, strong reservoir heterogeneity, and complex seismic response characteristics, making it difficult to interpret stratigraphic sequence by well-seismic combined seismic interpretation.
In traditional seismic interpretation, each horizon can be tracked and interpreted by manual or partial automatic tracking, which is a very heavy research work. This paper divides the three-dimensional seismic data into multiple grids by limiting the adjacent seismic traces as one panel, introducing the concept of cost function minimization, and connecting the horizons of each panel in the order from early to late together, and a global stratigraphic model with a relative geological age is established by means of humancomputer interaction and intelligent interpretation. By connecting the sampling points of each seismic event axis, the horizon interpretation of each event axis under the current seismic data resolution conditions is realized, thereby establishing a continuous sequence stratigraphic model, which 


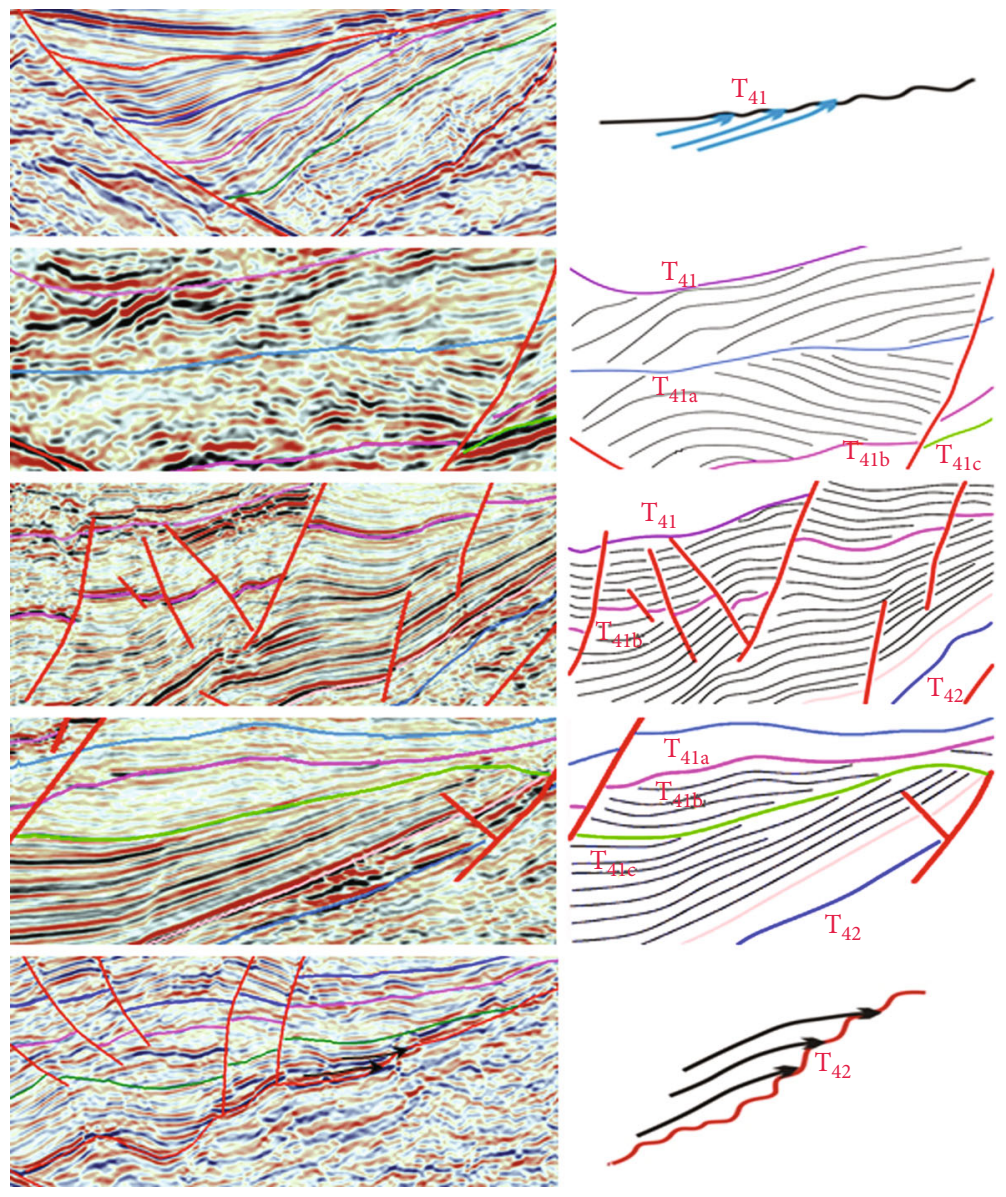

Figure 1: Sequence interface characteristics of the level 3 seismic in the Shahezi Formation.

can be extracted from this stratigraphic model, and any one of the seismic horizons interpreted by the high-frequency sequence is derived. These horizons provide the basis for the combination of the horizontal resolution and the vertical resolution of subsequent reservoir predictions.

The Xujiaweizi fault depression is located in the northern Songliao Basin, spreading in the NNW direction. The east side forms a slope transition with the ShangjiaChaoyanggou uplift belt, and the west side is separated from the central paleouplift belt by faults. Large-scale strike-slip activities began in the third member of Yingcheng Formation, Xuzhong fault (active in the early Yingcheng Formation), Xuxi depression-controlled fault (developed in the Huoshiling Formation period), large-scale extension, and rifting during the deposition of Shahezi). These three main faults (belts) control the west fault and east super compound skip-like fault depression [4].

The Shahezi Formation is a sedimentary strata in the rifting period, and its sequence development is significantly affected by the activities of the controlled faults. On the seismic profile, the top interface $T_{41}$ and the bottom interface $T_{42}$ of the Shahezi subgroup can be determined according to the characteristics of regional unconformity onlap or truncation seismic reflections. These two regional seismic markers correspond to regional unconformities and can be continuously compared and tracked [5]. The third-order sequence interface in the study area has the following characteristics on the seismic profile: (1) in the upper part of the slope break zone near the provenance, the seismic wave group appears to be truncated or eroded and filled; (2) the seismic wave group in the slope break zone is characterized by overlap and visual truncation, (3) there are obvious differences in seismic reflection characteristics between the strata above and below the event axis of strong amplitude reflection, and the identification marks divide the Shahezi subgroup from bottom to top into five three-level sequence interfaces: $T_{42}, T_{41 c}, T_{41 b}, T_{41 a}$, and $T_{41}$. The Shahezi subgroup is divided into four three-level sequences, $\mathrm{Sq} 1$ to Sq4 (Figure 1).

$T_{42}$ is the bottom boundary of the Shahezi Formation. Below the interface is usually the Huoshiling Formation volcanic rock deposits. A large number of overlay deposits can be seen above the interface, and distinct reflection structures can be seen above and below the interface.

$T_{41 c}$ is the sequence boundary between Sq2 and Sq1 of the Shahezi Formation. Some foreset deposition seismic facies can be seen above the interface, and truncation seismic reflection characteristic can be seen locally.

$T_{41 b}$ is the sequence boundary between Sq3 and Sq2 of the Shahezi Formation. The interface is locally characterized 


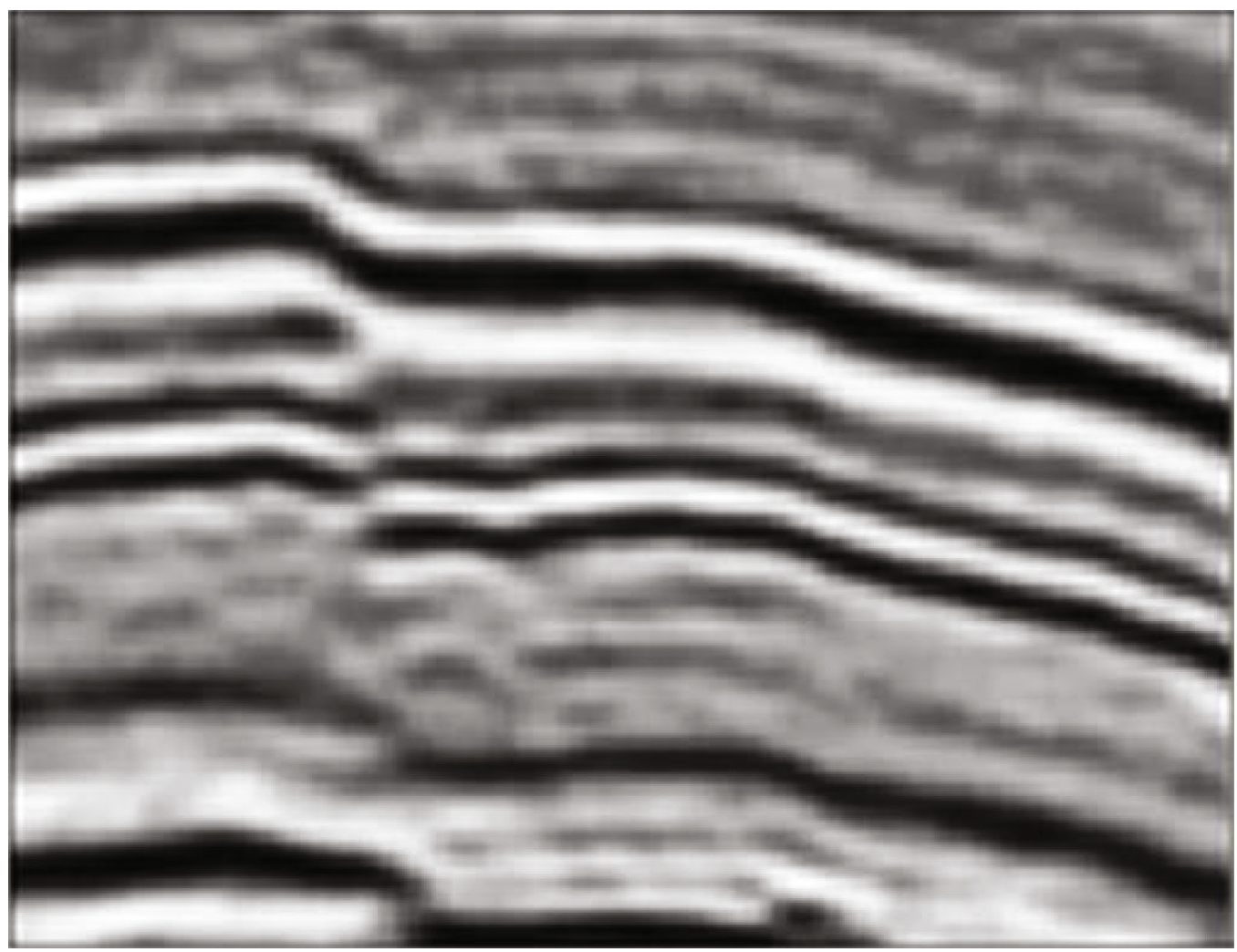

Figure 2: Seismic data, sectional view of the mesh panel model.

by strong reflection peaks, and some foreset deposition seismic facies and truncation seismic reflection characteristic can be seen above the interface.

$T_{41 a}$ is the sequence boundary between Sq4 and Sq3 of the Shahezi Formation, the truncation features can be seen in the local uplift position, and the overlap or foreset features can be seen above part of the boundary.

$T_{41}$ is the top boundary of the Shahezi Formation. Above the interface is mainly the Yingcheng Formation volcanic rock and below the target layer clastic rock. In the whole area, the surface of this interface on the seismic section is mostly the erosion of the underlying strata.

\section{Materials and Methods}

The human-computer interaction intelligent high-frequency sequence interpretation is through continuous addition of geological knowledge and repeated iterations to finally build a global stratigraphic model with a relative geological age. Any horizon picked from the global stratigraphic model represents one of the different high frequency sequence boundaries according to the well calibration.

2.1. Sequence Stratigraphic Model Building Technology. In the process of human-computer interaction intelligent high-frequency sequence interpretation [6-8], for each panel of the grid panel model, connect each panel to form the seismic reflection horizon of each isochronous interface. The connection method determines the different interpretation schemes of crosswell seismic data (Figures 2-5).
In the calculation process of the grid panel model, the calculation unit is established by defining the horizontal and vertical calculation time windows of the seismic data volume. The horizontal comparison unit refers to the use of several seismic data as a panel, and the vertical comparison unit refers to the peak, trough, or inflection point of the seismic trace waveform that defines the reflection characteristics of the event axis position that need to be interpreted (Figure 6).

In a data-driven way, according to the order from early to late, according to the principle of global inheritance of sedimentary strata, different panels are connected, and each type of global connection under the constraints of large grid horizons and faults is interpreted. The plan calculates the cost function.

$$
\text { Cost }=\sum_{i=1}^{N} \sum_{j=1}^{N}\left[\frac{1}{\sigma \sqrt{2 \pi}} \exp ^{\frac{-(p(i)-p(j))^{2}}{2 \sigma^{2}}} \operatorname{Dst}\left(V_{i}, V_{j}\right)\right] .
$$

In the cost function formula, $N$ is the number of sample points in a grid node, and $i$ and $j$ are used to describe the position of the sample points. The cost function takes into account the similarity and relative distance between nodes. Through the principle of cost function minimization, the corresponding model connecting these nodes is selected to realize the establishment of the global sequence stratigraphic model. This grid model is the optimization of the sequence stratigraphic model. It is iteratively optimized by continuously adding geological knowledge. Through continuous 


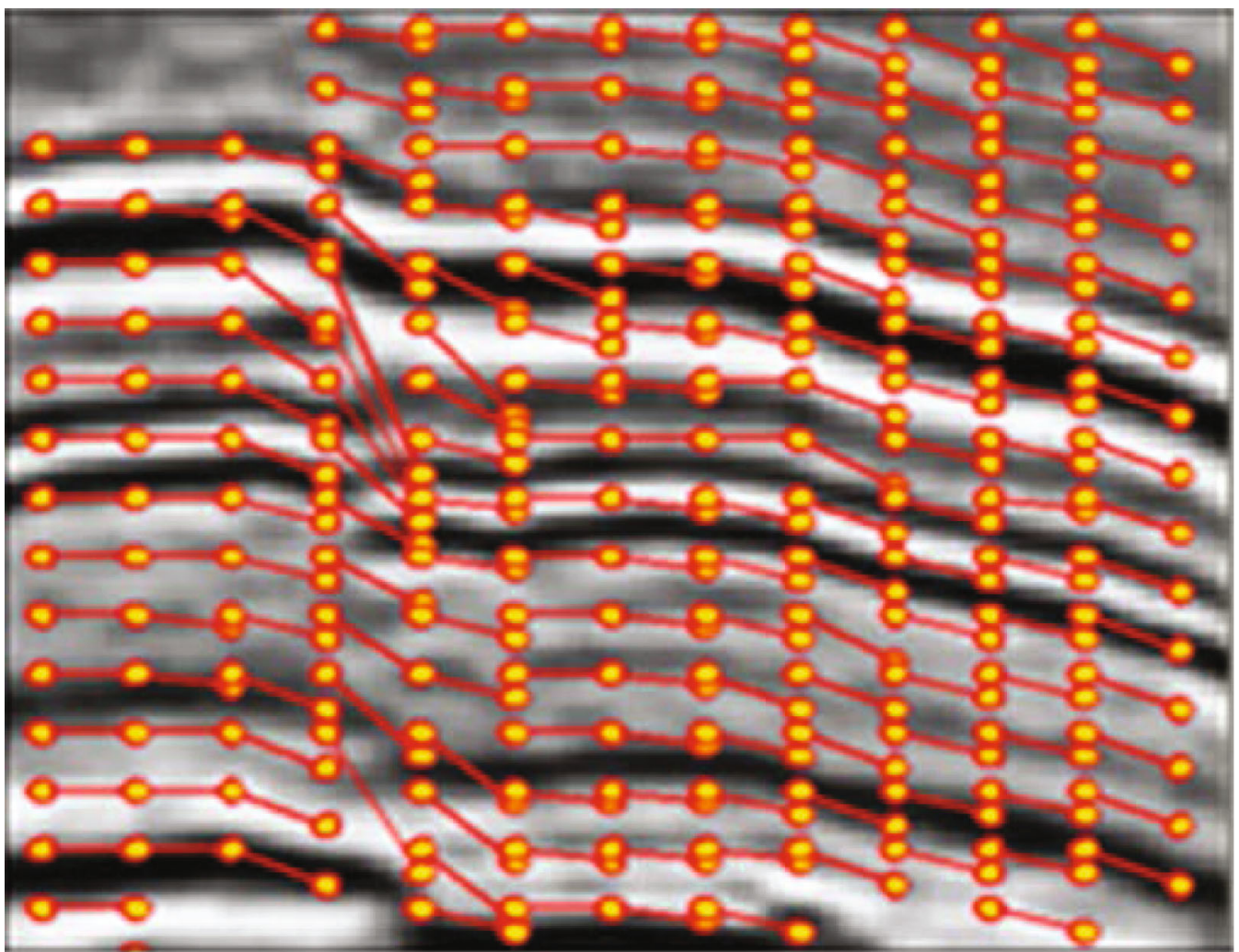

FIgUre 3: Mesh face model 1, sectional view of the mesh panel model.

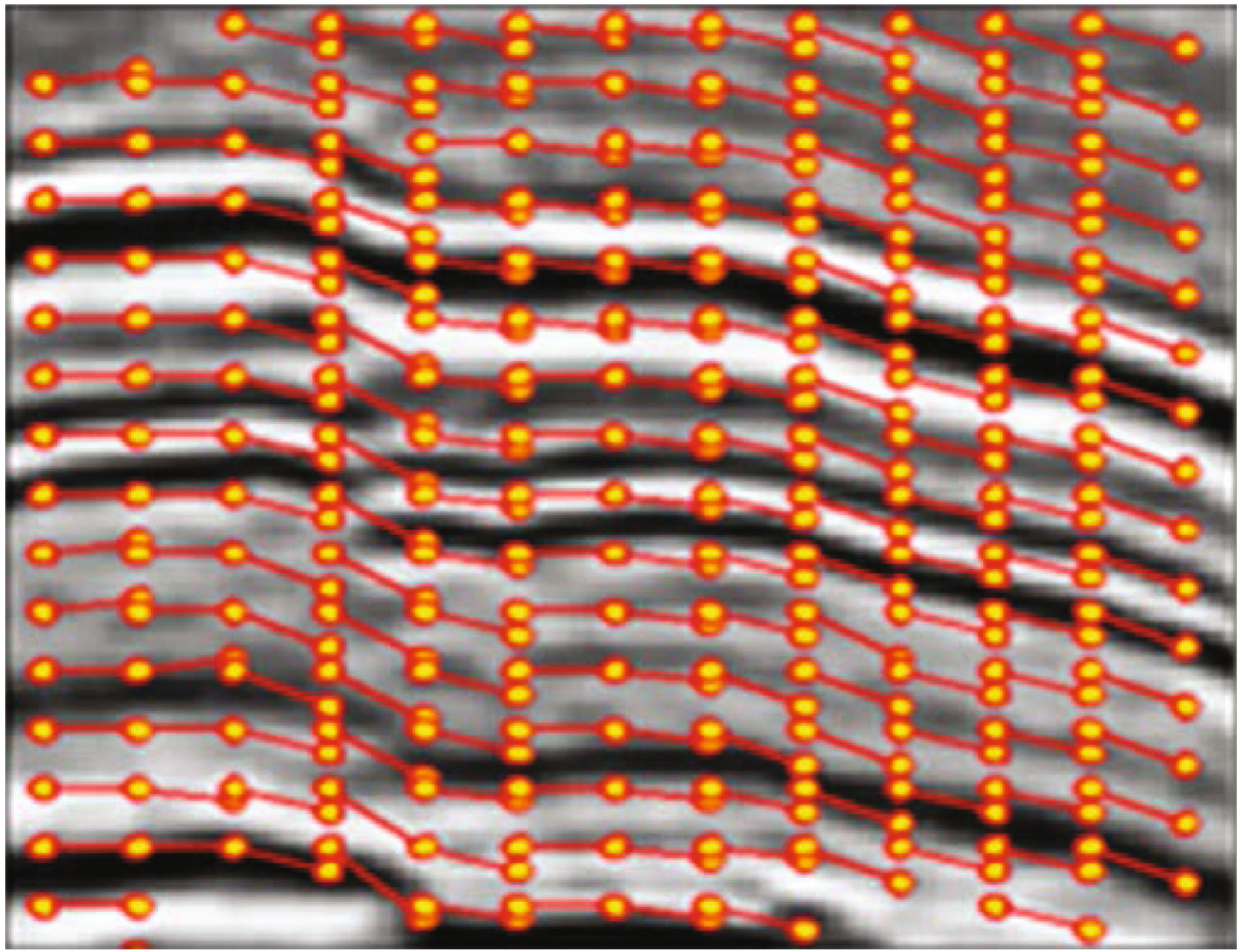

FIgUre 4: Mesh face model 2, sectional view of the mesh panel model. 


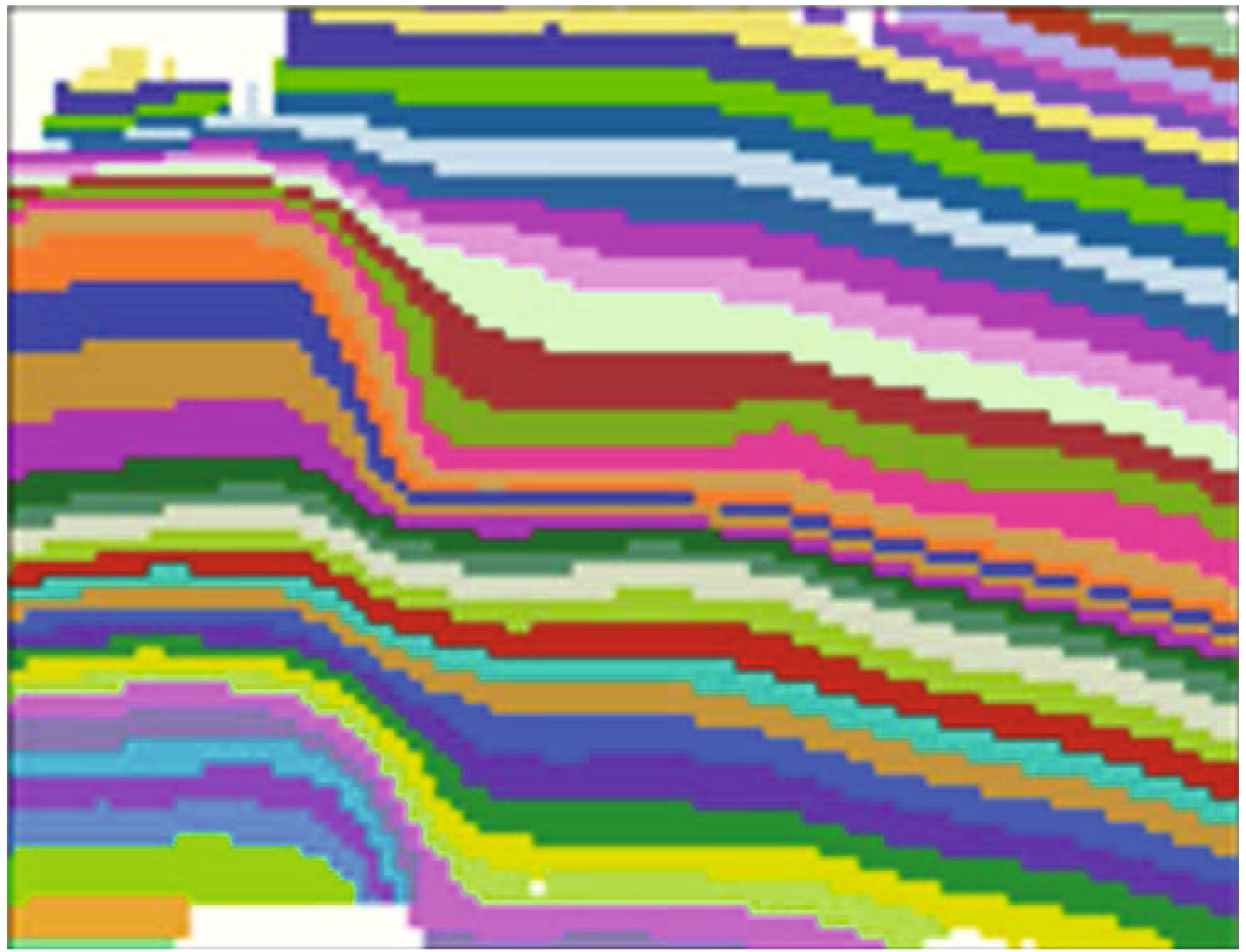

FIGURE 5: Stratigraphic model, sectional view of the mesh panel model.

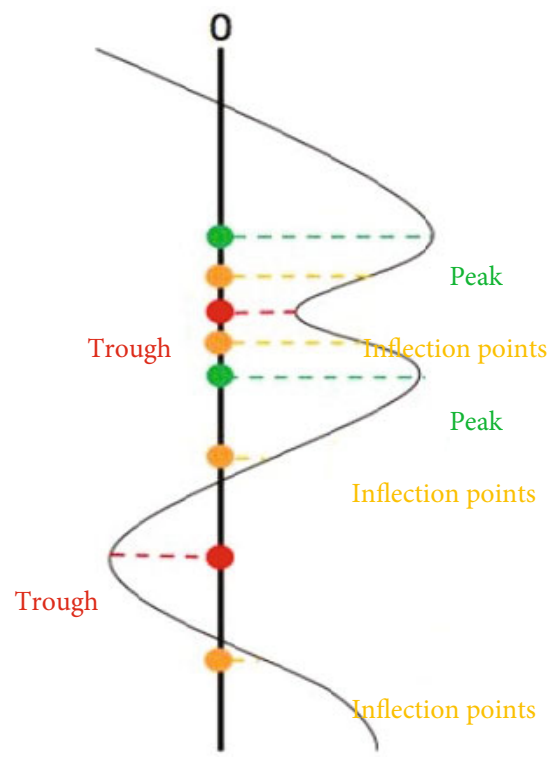

FIGURE 6: Schematic diagram of the waveform reflection position of seismic data.

indepth knowledge, reasonable faults are added, and a certain layer picked up as a standard layer is adjusted. After these new constraints, iteratively calculate a new threedimensional stratigraphic model. In this process, the experience of the interpreter also plays a vital role.
2.2. Sequence Boundary Recognition Technology. In the process of human-computer interaction intelligent highfrequency sequence interpretation, each iteration will generate a global stratigraphic model relative to the geological age, so that the corresponding sequence boundary attributes can 


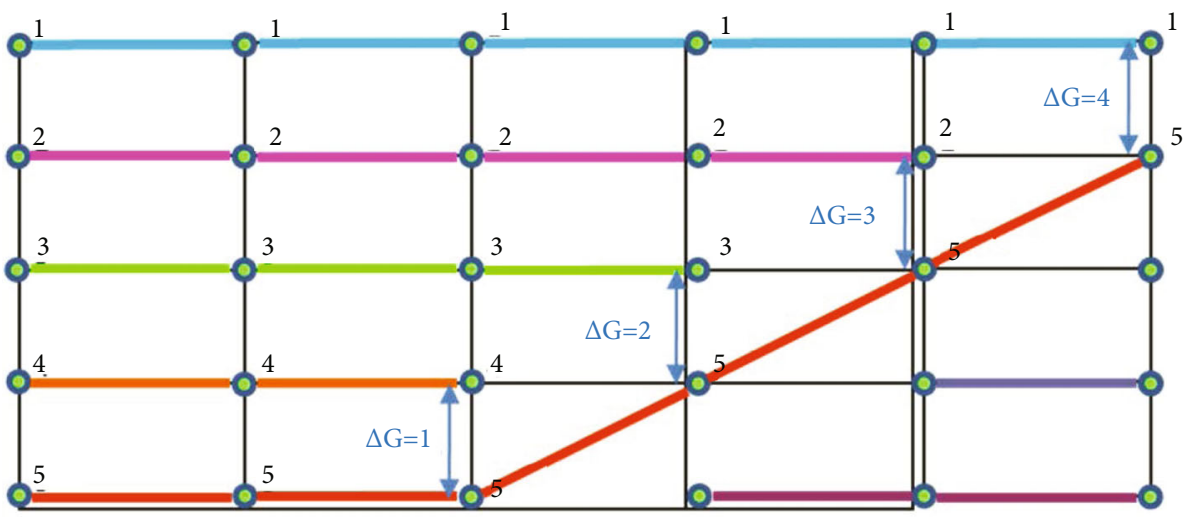

FIGURE 7: Schematic diagram of sequence boundary recognition attribute calculation.

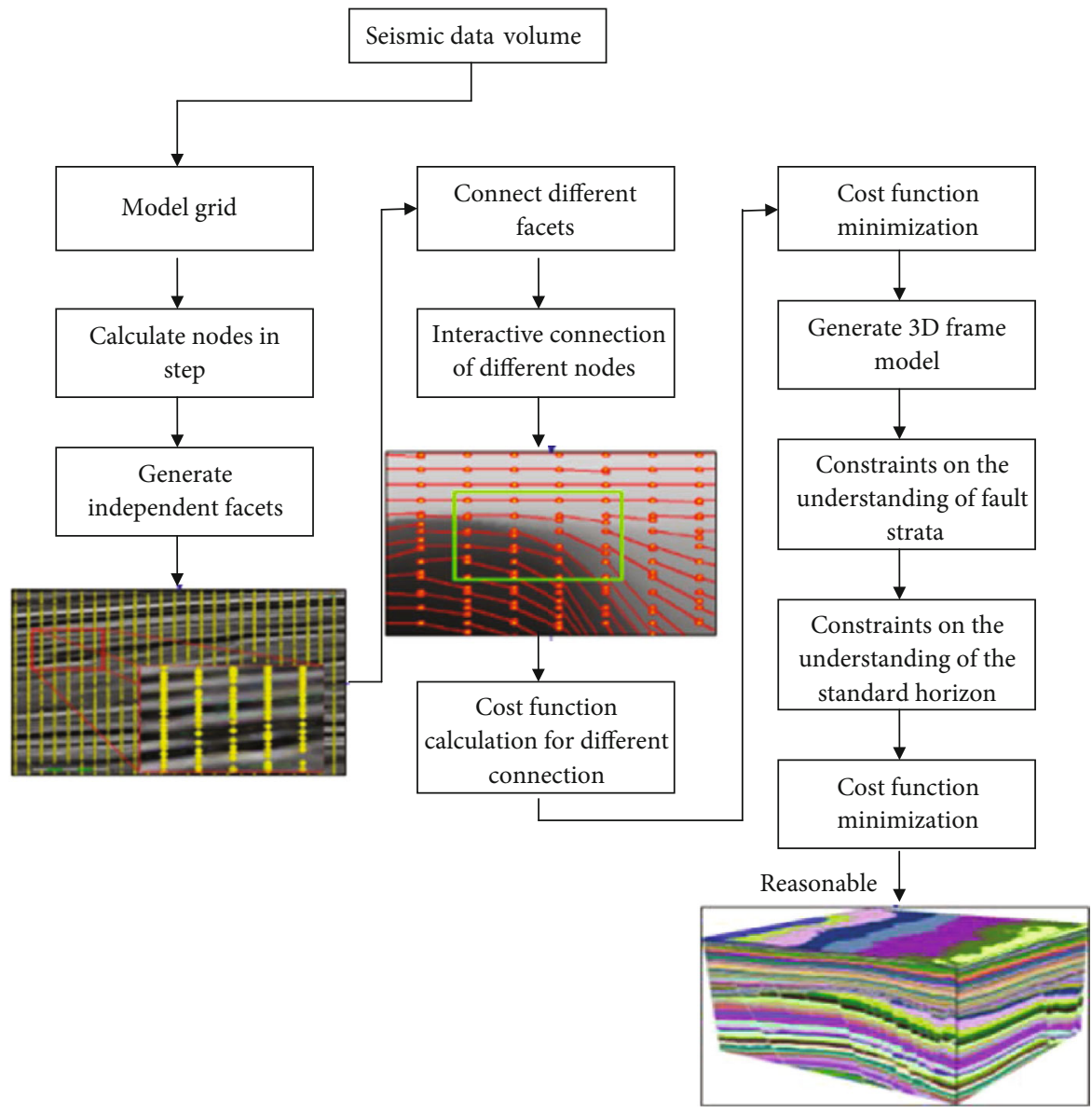

FIgURE 8: Intelligent explanation flow chart of human-computer interaction.

be calculated [9-12], and the calculation formula is as follows:

$$
\text { Thinning }=\frac{\Delta \mathrm{RGT}}{\Delta Z}
$$

Among them, RGT (a vertically continuous model of relative geological time) represents each seismic reflection horizon in the stratigraphic model of the relative geological age, and $\Delta Z$ is the time difference between every two horizons. In the sequence boundary attribute profile, sedimentary phenomena such as discontinuity, denudation, and dense sections show high values (Figure 7). Due to the horizontal changes of strata such as stratigraphic pinch, the relative geological age difference between the same two sampling points during two-way travel is different, which results in different magnitudes of sequence boundary attribute values. It can be seen that the sequence boundary attributes can identify sedimentary phenomena such as stratum missing or sedimentary discontinuity. 
SS3

SS9dy

SS102

DS20

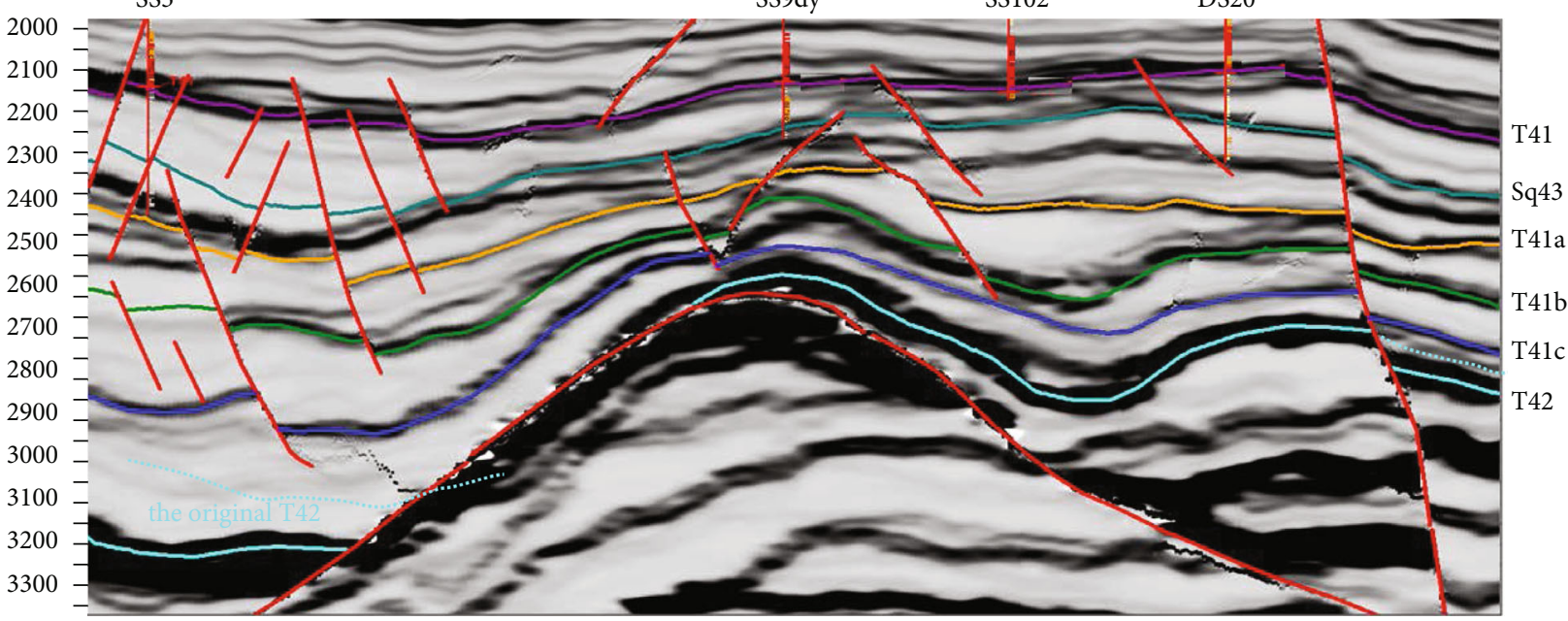

FIgURE 9: The third- and fourth-order sequence boundary recognition attribute profile of the Shahezi Formation.

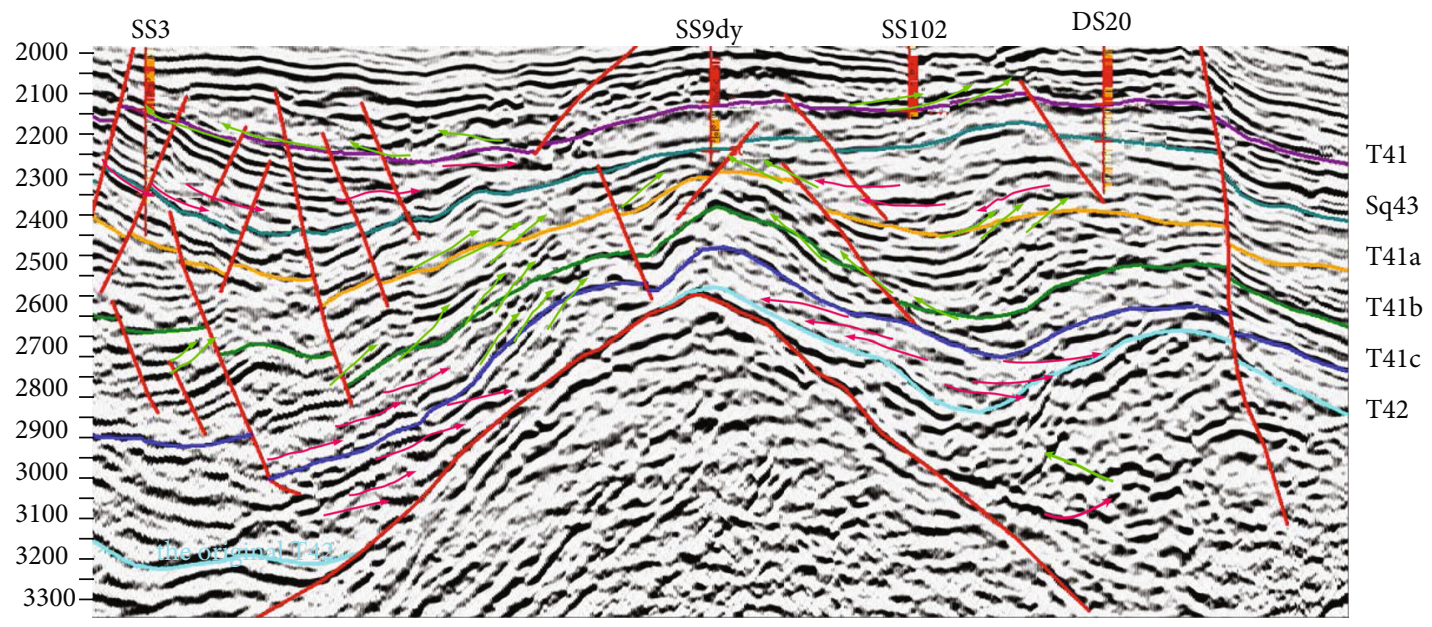

Figure 10: Seismic interpretation section of the third and fourth levels of the Shahezi Formation.

\section{Results and Discussion}

In this study, the thickness of the third-order sequence stratigraphy is generally 300 to $800 \mathrm{~m} \mathrm{[13-15].} \mathrm{In} \mathrm{order} \mathrm{to} \mathrm{meet}$ the needs of prediction of thin glutenite reservoirs of about $10 \mathrm{~m}$, a more refined high-frequency sequence stratigraphic framework needs to be established, see Figure 8 .

The unconformity contact relationship of the seismic event axis is the most reliable sequence boundary [16-18]. On the seismic profile of the study area, the seismic reflections corresponding to the upper and lower strata of the third-order sequence interface have obvious unconformity contact characteristics, and the fourth-order sequence unconformity features can be seen locally in the interface. The application of this technology in the study area has significantly improved the accuracy and efficiency of the horizon interpretation. Taking the interpretation of the $T_{42}$ reflective layer on the bottom of the Shahezi Formation as an example, the original interpretation plan (blue dotted line) and the new plan (blue solid line) are in the depression area. The dotted line is shallower than the solid line
(Figure 9). The newly completed drilling confirms that the seismic characteristics of the new interpretation scheme are more reasonable (Figure 10) [19].

The fifth-order sequence (red dashed line) appears as a local water inlet surface on the single-well logging curve; the seismic is a relatively integrated interface within the fourth-order sequence interface. The event axis is generally stable and easy to trace, but a large set of thick layers of the chaotic reflection characteristics corresponding to glutenite are difficult to track, and they are generally tracked according to the characteristics of the fault distance and the thickness of the formation. After the skeleton seismic profile is established, the three-dimensional seismic data is scanned globally, under the constraints of the horizon and fault interpretation results of the large grid, through the principle of cost function minimization, humancomputer interaction intelligent interpretation, and interpretation by adjusting horizons and faults achievements and continuous iterations that have established a global stratigraphic model with a relative geological age [20, 21]. It is calibrated by well layer, and the five-level sequence 


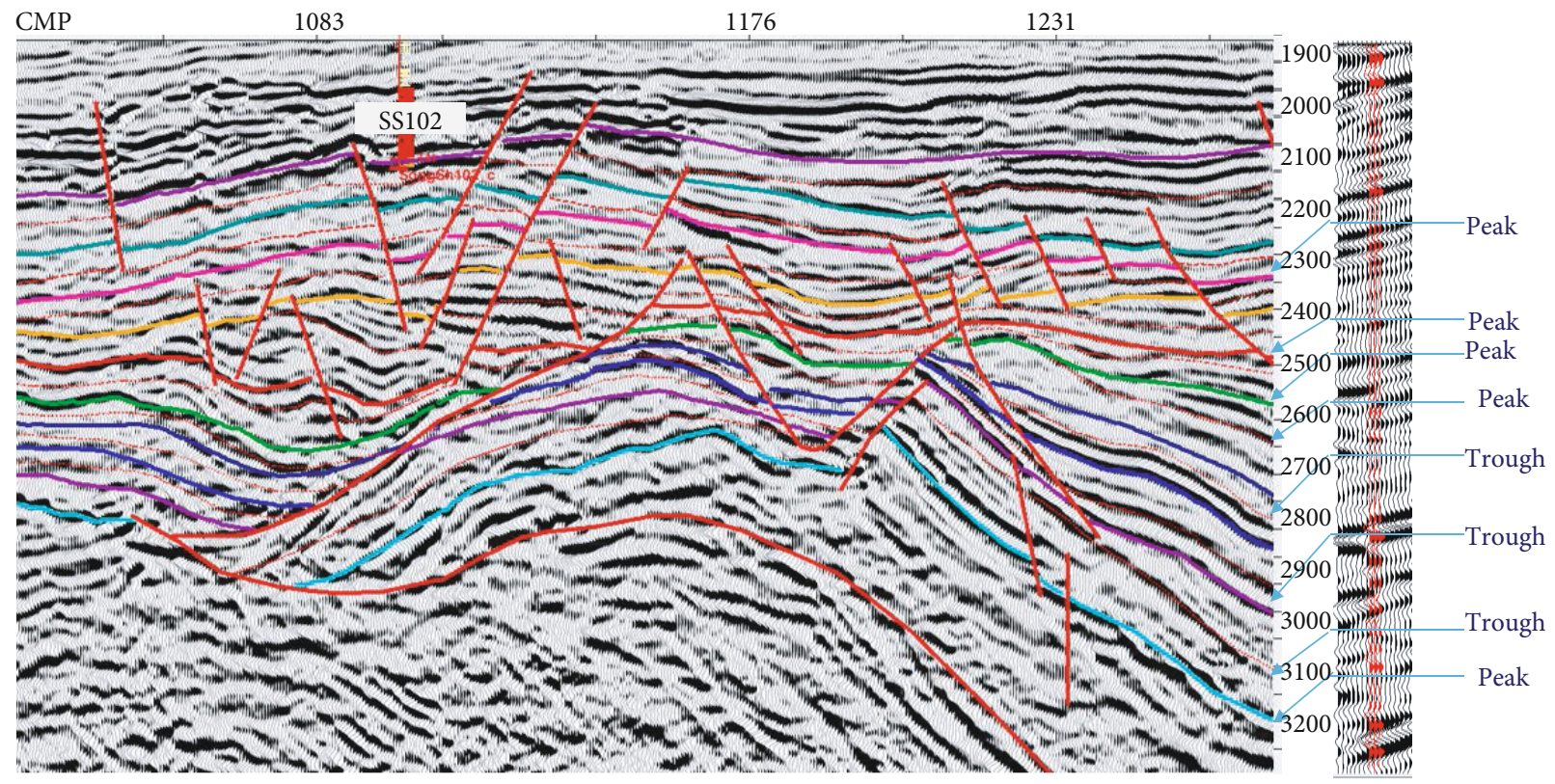

FIGURE 11: Seismic interpretation section of the fifth-order sequence of the Shahezi Formation.

seismic interpretation layer is picked out from the global stratigraphic model.

Through the fine interpretation of the five-level sequence, the Shahezi Formation is divided into 18 fivelevel sequence units vertically, and the thickness of the vertical stratigraphic unit is refined to $60-120 \mathrm{~m}$, and a finer isochronous sequence framework is established (Figure 11). It provides a basis for the combination of horizontal resolution and vertical resolution of reservoir prediction.

\section{Conclusions}

This study takes 3D seismic data from the $170 \mathrm{~km}^{2}$ study area in the northern Xujiaweizi fault depression as an example. Aiming at the complex structure of the continental faulted lake basin, the global optimization algorithm is used to highlight the cost function of stratigraphic sedimentation with global inheritance and the principle of minimization. On the basis of the constraints of fault interpretation results, through iterative adjustment of horizon and fault interpretation results, the high-frequency sequence stratigraphic interpretation is realized by using global sequence stratigraphic model building technology.

(1) Accurate fault interpretation results, as well as the depth of the interpreter's geological knowledge of the study area, directly affect the accuracy and efficiency of the sequence stratigraphic model

(2) Global optimization of sequence stratigraphic seismic interpretation technology improves the accuracy and efficiency of sequence stratigraphic interpretation, realizes the interpretation of the current seismic data resolution for each event horizon, and establishes a continuous sequence stratigraphy based on $3 \mathrm{D}$ seismic data. The model provides a basis for the combination of horizontal resolution and vertical resolution for subsequent reservoir prediction

\section{Data Availability}

All data included in this study are available upon request by contact with the corresponding author.

\section{Conflicts of Interest}

The authors declare no conflict of interest.

\section{Acknowledgments}

We gratefully acknowledge the Northeast Petroleum University and National Natural Science Foundation of China (41774126) for their financial support.

\section{References}

[1] J. Lu and L. Chao, "Accumulation conditions and resource potential of tight glutenite gas in fault depression basins: a case study on Lower Cretaceous Shahezi Formation in Xujiaweizi fault depression, Songliao Basin," China Petroleum Exploration, vol. 21, no. 2, pp. 53-60, 2016.

[2] H. H. Du Jinhu, Y. Tao, L. Jianzhong, H. Fuxi, G. Bincheng, and Y. Weipeng, "China's tight oil exploration progress and challenges," China Petroleum Exploration, vol. 19, no. 1, pp. 1-9, 2014.

[3] Q. Guiqiang, "Research status and ideas of high-precision sequence stratigraphy in continental rift basins," Petroleum Geology and Recovery Efficiency, vol. 12, no. 3, pp. 1-4, 2005.

[4] N. Wen, "Xujiaweizi fault depression-controlling fault activity characteristics and its controlling effect on fault depression," Daqing Petroleum Geology and Development, vol. 38, no. 4, pp. $38-44,2019$. 
[5] C. Quansheng, Study on the Development Characteristics of Sequence Stratigraphic Framework and Sedimentary System of Small Continental Faulted Lake Basin, [Ph.D. thesis], Doctoral Dissertation of Yangtze University, 2017.

[6] S. Lacaze, F. Pauget, M. Lopez, A. Gay, and M. Mangue, "Seismicstratigraphic interpretation from a geological model - A north seacase study," in 2011 SEG Annual Meeting, San Antonio, Texas, 2011.

[7] N. Daynac, S. Lacaze, and F. Pauget, "Interpretation of complex faulted deposits in the North Sea using the relative geological time model," First Break, vol. 34, no. 5, pp. 3844, 2016.

[8] B. Durot, M. M. Mangue, B. L. Luquet, J. P. A. Adam, and N. D. Daynac, "Innovative and interactive methods emphasizing geological events through spectral decomposition new Zealand case study," in 79th EAGE Conference and Exhibition 2017 (Vol. 2017, No. 1, pp. 1-5), pp. 1-5, 2017.

[9] F. Pauget, S. Lacaze, and T. Valding, "A global approach to seismic interpretation base on cost function and minimization," in EG Technical Program Expanded Abstracts 2009, pp. 2592-2596, Denver Co, 2009.

[10] Z. Xiaodong, Y. Jing, and Z. Dazhi, “Tight gas accumulation conditions and exploration prospects of Shahezi formation in Xujiaweizi fault depression," Daqing Petroleum Geology and Development, vol. 33, no. 5, pp. 86-91, 2014.

[11] Y. Wang and R. Song, "The application of sequence seismology in the internal structure analysis of strata," Geophysical Prospecting for Petroleum, vol. S1, pp. 33-40, 1997.

[12] X. Zhang and L. Qiu, "Using wavelet transform to divide sequence stratigraphy of logging data," in Abstracts of the 12th National Conference on paleogeography and sedimentology, pp. 100-108, 2012.

[13] Y. Wang, Q. Wang, and X. Qing, “Ordovician standardized sequence stratigraphy and lithofacies paleogeographic pattern in Ordos," in Proceedings of 2015 annual meeting of Chinese Geological Society (Volume II), pp. 212-220, 2015.

[14] Z. Li, M. Wang, J. Yu et al., "Research on coal bearing strata sedimentation, sequence stratigraphy and coal accumulation law in Shandong and adjacent areas," in 2003 China Coal Industry Association Science and technology award winning project collection, pp. 216-225, 2004.

[15] Z. Jiang, J. Yan, and L. Zhang, "Thoughts on the study of sequence stratigraphy and deep-water sedimentation - revision of sequence stratigraphy by geological/sedimentary accommodation space transformation," in Proceedings of the 10th Annual Conference of Chinese society of mineralogy, petrogeochemistry, pp. 111-120, 2005.

[16] F. Yin, F. Wan, and M. Chen, "Sequence stratigraphy in the evolution of foreland basins in the upper Yangtze region during Caledonian," in Abstracts of the 2001 National sedimentological Congress, pp. 213-221, 2001.

[17] R. Guo and A. Luo, "Application of fractal dimension in well logging sequence stratigraphy," in Proceedings of the 12th annual meeting of Chinese Geophysical Society in 1996, pp. 135-145, 1996.

[18] Q. Li, "A method for calculating the characteristic quantity of well logging sequence stratigraphy," in Proceedings of the 12th annual meeting of Chinese Geophysical Society in 1996, pp. 213-223, 1996.

[19] T. Zhu, X. Feng, G. Zou, and J. Li, "Late Paleozoic sequence stratigraphy and sea level change in the Himalayan region of southern Tibet," in Abstracts of the Symposium on geology, resources and environment of the Qinghai Tibet Plateau and its adjacent areas, pp. 159-168, 2003.

[20] R. Jinfeng, H. Wang, L. Xiaolong, and Z. Shue, "Research and application of automatic division of high-precision sequence stratigraphy based on wavelet transform," in Abstracts of the 12th National Conference on paleogeography and sedimentology, pp. 201-210, 2012.

[21] Y. Jinquan, X. Liang, X. Sheng, Z. Yang, and Q. Li, “A study on the relationship between Mesozoic Cenozoic sequence stratigraphy and basin mountain transition in the middle Yangtze Region," in Abstracts of the third national sedimentological Congress, pp. 220-230, 2004. 